Full Paper: This study reports for the first time on the enhancement of the bleaching effect achieved on cotton using laccase enzyme. Laccases applied in short-time batchwise or pad-dry processes prior to conventional peroxide bleaching, improved the end fabric whiteness. The whiteness level reached in the combined enzymatic/peroxide process was comparable to the whiteness in two consecutive peroxide bleaches.

Effect of 10 min laccase pre-treatment at $60^{\circ} \mathrm{C}, \mathrm{pH} 5$ on fabrics whiteness before and after a conventional hydrogen peroxide bleaching.

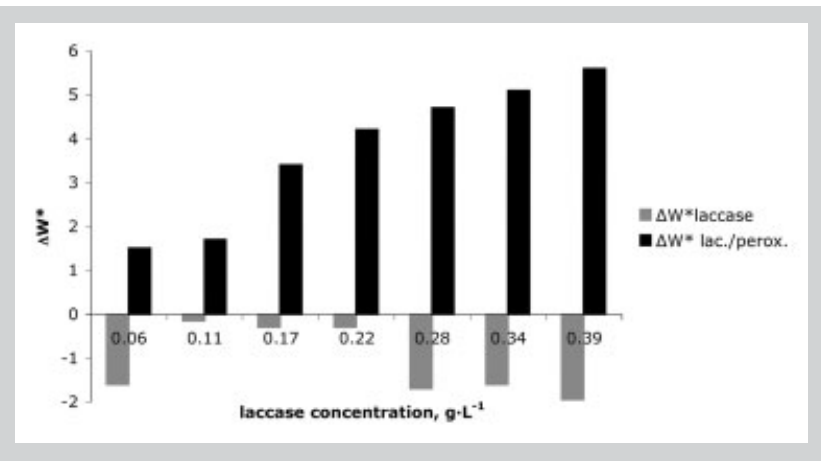

\title{
Laccases to Improve the Whiteness in a Conventional Bleaching of Cotton
}

\author{
Tzanko Tzanov, ${ }^{1}$ Carlos Basto, ${ }^{1}$ Georg M. Gübitz, ${ }^{2}$ Artur Cavaco-Paulo* ${ }^{1}$ \\ ${ }^{1}$ Departamento de Engenharia Têxtil, Universidade do Minho, Campus de Azurém, 4800-058, Guimarães, Portugal \\ Fax: +351 253 510293; E-mail: artur@det.uminho.pt \\ ${ }^{2}$ Graz University of Technology, Dept. of Environmental Biotechnology, 8010 Graz, Austria
}

Received: March 27, 2003; Revised: July 7, 2003; Accepted: July 8, 2003; DOI: 10.1002/mame.200300100

Keywords: bleaching; enzymes; fibers

\section{Introduction}

Laccases (EC 1.10.3.2) are multi-copper enzymes, which catalyze the oxidation of a wide range of inorganic and organic substances, using oxygen as an electron acceptor. ${ }^{[1]}$ The laccase molecule contains four copper atoms per monomer, bound to three redox sites (T1, T2, and T3). The mechanism of the laccase catalysis involves binding the reducing substrate to the $\mathrm{T} 1$ active centre, and reduction of the $\mathrm{T} 1-\mathrm{Cu}$ (II) to $\mathrm{Cu}$ (I). The oxidation of a reducing substrate typically involves formation of a free (cation) radical after the transfer of a single electron to laccase. ${ }^{[2]}$

Laccases have found various biotechnological and environmental applications, i.e. removing toxic compounds from polluted effluents through oxidative enzymatic coupling of the contaminants leading to insoluble complex structures, or as biosensors for phenols. ${ }^{[3-9]}$ Laccases have been extensively used in delignification, demethylation, and thereby bleaching of kraft pulp. ${ }^{[1,8,10-12]}$ Capability of laccases to act on chromophore compounds suggested their application in industrial decolorization processes. ${ }^{[12-16]}$ However, these enzymes have never been used for bleaching of textiles. In the conventional bleaching process of cellulosic fiber materials different chlorine and oxygen containing oxidizing agents are used. The whiteness level targeted in the bleaching process depends on the end use of the fabrics. However, when higher whiteness is needed it is necessary to perform a repeated oxidizing treatment, i.e. short time pre-bleaching with hypochlorite, followed by peroxide bleaching, or two consecutive peroxide bleaches. Appropriate enzymatic processes at milder conditions might replace these traditionally high chemical, energy and water consuming textile operations. The objective of this research was to investigate the bleaching ability of the laccases as an alternative to the conventional chemical oxidants.

\section{Experimental Part}

\section{Textile Substrate}

The textile material used in the experiments was alkali scoured, twill weave, $120 \mathrm{~g} \cdot \mathrm{m}^{-2}, 100 \%$ cotton fabric.

\section{Laccase Activity Assay}

The assay mixture contains $0.5 \times 10^{-3}$ м 2,2'-azinobis(3ethylbenzthiazoline-6-sulfonate) (ABTS) provided by Sigma, $0.1 \mathrm{~m}$ sodium acetate buffer $\mathrm{pH} 5$, and a suitable amount of enzyme. Laccase activity was assayed spectrophotometrically 
by measuring the increase of the absorbance at $420 \mathrm{~nm}$ $\left(\varepsilon_{420}=3.6 \times 10^{4} \mathrm{M}^{-1} \cdot \mathrm{cm}^{-1}\right)$ due to the oxidation of ABTS. ${ }^{[17]}$ Enzyme activity (U) was defined as $\mu \mathrm{mol}$ of substrate oxidized per min.

\section{Laccase Pre-Treatment and Conventional Bleaching Process}

The fabrics were treated with laccase (EC 1.10.3.2, Trametes villosa laccase, $10 \mathrm{~g} \cdot \mathrm{L}^{-1}$ protein, from Novo Nordisk) in $0.1 \mathrm{M}$ acetate buffer $\mathrm{pH} \mathrm{5}$, at the temperature for maximum enzyme activity. Thorough washing at boil followed the enzyme pretreatment in order to remove the protein. Then the fabrics were bleached following the recipe: $1.75 \mathrm{~g} \cdot \mathrm{L}^{-1} \mathrm{Na}$-silicate $(\mathrm{BDH})$, $0.5 \mathrm{~g} \cdot \mathrm{L}^{-1} \mathrm{Na}_{2} \mathrm{CO}_{3}, 1 \mathrm{~g} \cdot \mathrm{L}^{-1} \mathrm{NaOH}$ (Merck), and $2 \mathrm{~g} \cdot \mathrm{L}^{-1}$ $35 \% \mathrm{H}_{2} \mathrm{O}_{2}$ (Sigma). The bleaching experiments were carried out at $95^{\circ} \mathrm{C}$ for $1 \mathrm{~h}$, in an Ahiba Spectradye-Datacolor dyeing apparatus at liquor to fabric ratio 20:1.

\section{Oxygen Consumption in Laccase Reaction}

The oxygen consumption during the enzymatic reaction was followed by means of a CellOx 325 oxygen sensor, (from WTW GmbH \& Co. KG) in a thermostated, hermetically sealed vessel. Cotton samples $(0.1$ and $0.2 \mathrm{~g})$ were treated with $0.1 \mathrm{mg} \cdot \mathrm{mL}^{-1}$ laccase in $30 \mathrm{~mL}$ acetate buffer $\mathrm{pH} 5$, at $35^{\circ} \mathrm{C}$, for $60 \mathrm{~min}$. Data were acquired every $30 \mathrm{sec}$. Gaseous nitrogen was injected into the vessel to liberate the oxygen in the gaseous phase and to avoid its transfer to the liquid phase. The data for the oxygen consumption represents mean values from four measurements with less than $10 \%$ of error.

\section{Whiteness of the Textile Material}

The whiteness index (Berger) $\left(W^{*}\right)$ of the fabrics was determined using a reflectance measuring Datacolor apparatus at standard illuminant $\mathrm{D}_{65}$ (LAV/Spec. Excl., d/8, $\left.\mathrm{D}_{65} / 10^{\circ}\right)$.

\section{Decolorization of Dyed Textiles with Laccase}

Fabrics samples, previously dyed with Reactive Yellow 160, Reactive Orange 16 and Reactive Green 19 (from Everlight Chem. Ind.), were subjected to laccase pre-treatment (1h, $50{ }^{\circ} \mathrm{C}, \mathrm{pH} 5,0.5 \mathrm{~g} \cdot \mathrm{L}^{-1}$ laccase) and afterward to conventional oxidative bleaching. The color of the fabrics was assessed in terms of $K / S$ values. $K / S$ is the Kubelka-Munk relationship, where $K$ is an adsorption coefficient and $S$ is a scattering coefficient. This relationship is applied to textiles under the assumption that light scattering is due to the fibers, while adsorption of light is due to the colorant. All whiteness and $K / S$ determinations were in triplicate experiments at 5 different places on the surface of the samples and results shown are mean values with less than $2 \%$ of error.

\section{Results and Discussion}

\section{Experimental Conditions for Laccase Application}

The production of high quality textile materials should be coupled to processes carried out in reduced bath volumes,

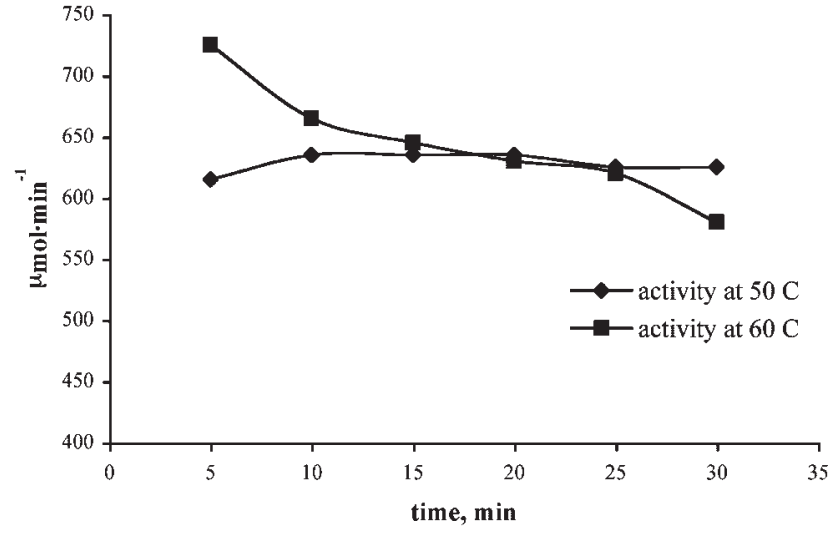

Figure 1. Laccase activity at 50 and $60^{\circ} \mathrm{C}$, measured against ABTS substrate, after incubation in $0.1 \mathrm{~m} \mathrm{Na}$-acetate buffer $\mathrm{pH} 5$ for up to $30 \mathrm{~min}$.

with low chemical dosage and short processing times. In continuous processes the longest time that the fabrics could spend in the machinery, depending on the construction, just exceeds $30 \mathrm{~min}$. The feasibility of an enzymatic lab scale process for industrial application will depend on the specific technology cycle adopted in the textile plant, and on the available machinery. The guidelines to set the experimental conditions for laccase application could be provided by the $\mathrm{pH}$ and temperature profiles of enzyme activity. The optimum temperatures for the enzymatic process lie between 50 and $60{ }^{\circ} \mathrm{C}$, and the appropriate $\mathrm{pH}$ is 5. For practical application of the biocatalyst it is important to know the decay of its activity during the process. The results revealed that the laccase was more stable at $50{ }^{\circ} \mathrm{C}$ with insignificant loss of activity during $30 \mathrm{~min}$ (Figure 1). Based on these experimental data the enzymatic treatment should be performed preferentially between 50 and $60{ }^{\circ} \mathrm{C}$, and over a period of up to $30 \mathrm{~min}$. It should be noticed that the activity of the enzymes is normally determined on soluble substrates in a homogenous catalysis reaction, which differs significantly from the application of enzymes in the textile industry, where the substrate is insoluble, and the wet processes are characterized with high turbulence and mechanical agitation in the textile baths.

\section{Laccase Pre-Treatment and Bleaching Effect}

The bleaching capacity of laccase was tested in a short-time batchwise process, performed at the optimum enzyme catalysis temperature and $\mathrm{pH}$. The results in Figure 2 showed that the laccase pre-treatment alone did not improve fabrics whiteness, compared to the blank treated in buffer at the same reaction conditions $\left(\Delta W^{*}\right.$ was calculated as a difference between the whiteness index of the enzymatically-treated samples and the blank). Even more, the enzyme application deteriorated the whiteness of the textile material and apparently generated color. It is known that 


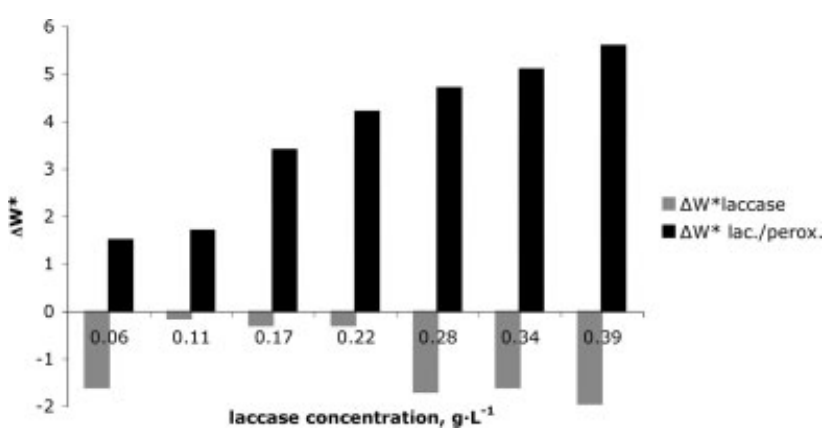

Figure 2. Effect of 10 min laccase pre-treatment at $60^{\circ} \mathrm{C}, \mathrm{pH} 5$ on fabrics whiteness before and after a conventional hydrogen peroxide bleaching.

the laccase could produce colored substances when suitable substrate is present. ${ }^{[18]}$ In the case of cotton the nature of the coloring matter present is not fully characterized, but it is believed that it is mainly due to nitrogen-free flavone pigments. These compounds are based on the flavonoid skeleton, which is a three rings molecule, two of them aromatic connected by heterocyclic centre ring. These pigments are normally removed only after oxidizing bleaching, however could be subjected to laccase-mediated oxidation. Lignin substances, remaining in the scoured cotton, might be substrates for the laccase as well. Surprisingly, after the hydrogen peroxide bleaching, the whiteness of the enzymatically pre-treated fabric was higher than the whiteness of the conventionally bleached fabric by 5.6 Berger units. The whiteness index improvement $\left(\Delta W_{\text {lac. }}^{*}\right.$ perox. $\left.=W_{\text {lac. } / \text { perox. }}^{*}-W_{\text {perox. }}^{*}\right)$ achieved in the combined enzymatic/peroxide bleaching process was comparable to the whiteness increase in two consecutive peroxide bleaches with $2 \mathrm{~g} \cdot \mathrm{L}^{-1} 35 \% \mathrm{H}_{2} \mathrm{O}_{2}$, at boil, $1 \mathrm{~h}$ each $\left(\Delta W^{*}=W_{2 \text { nd perox. }}^{*}-W_{1 \text { st perox. }}^{*}=6\right.$ units $)$. A possible explanation of this fact might be that the laccase transformed the cotton coloring matter in another colored substance, which was easier to remove during the oxidative bleaching. The advantage of the enzymatic process over the conventional bleaching was in terms of reduced time, energy and chemical consumption.

\section{Laccase Pre-Treatment at Elevated Temperature}

Impregnation of the fabrics with $1 \mathrm{~g} \cdot \mathrm{L}^{-1}$ laccase buffered solution on foulard and then incubation in a chamber at $100{ }^{\circ} \mathrm{C}$ (pad-dry process), for processing times between 1 and 5 min, showed a whiteness increase in the order of 5 Berger units after conventional peroxide bleaching (Table 1). Obviously the elevated temperature boosted the laccase activity and performance, shortening the pretreatment time.

\section{Oxygen Consumption in Laccase Reaction}

The consumption of oxygen in the presence of cotton cellulose is an indication for the occurrence of enzymati-
Table 1. Whiteness of fabrics pre-treated with laccase at elevated temperature and peroxide bleached afterwards.

\begin{tabular}{lccc}
\hline & \multicolumn{3}{c}{ Whiteness Berger } \\
\cline { 2 - 4 } & $1 \mathrm{~min}$ & $3 \mathrm{~min}$ & $5 \mathrm{~min}$ \\
\hline Blank treated in buffer & 55.56 & 57.58 & 59.60 \\
Sample & 61.62 & 63.64 & 65.66
\end{tabular}

cally-catalyzed reaction (Figure 3). The oxygen consumption increased with the increase of the amount of cotton substrate.

\section{Effect of the Laccase Pre-Treatment on the Oxidative Decolorization of Dyed Textiles}

In order to confirm the assumption that the laccase oxidized colored matter in cotton is more easily removable in an oxidative, peroxide bleaching, we bleached previously dyed cotton fabrics, which developed color or changed insignificantly after enzymatic application (Table 2). The decolorization of all laccase treated fabrics increased by 9 to $28 \%$ after the peroxide bleaching depending on the dye, compared to the fabrics, treated in buffer. These decolorization results are an indirect evidence for the occurrence of an enzyme-catalyzed process, affecting the dyes' chromophores and thereby facilitating the removal of the colored natural substances from the cotton cellulose in a subsequent oxidative bleaching. The exact mechanisms of the enzymeaided bleaching is to be further elucidated.

\section{Laccases Pre-Treatment to Reduce the Amount of Hydrogen Peroxide in Subsequent Bleaching}

Cotton samples (1 g each) were treated with laccases $\left(0.11 \mathrm{~g} \cdot \mathrm{L}^{-1}\right)$ in $50 \mathrm{~mL}$ acetate buffer $\mathrm{pH} 5$, at $60^{\circ} \mathrm{C}$ for

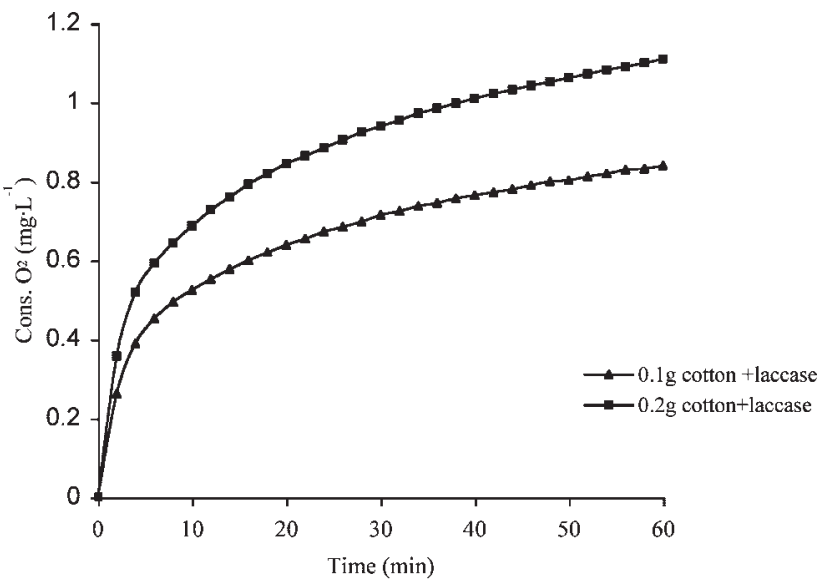

Figure 3. Oxygen consumption in laccase treatment of cotton, at $\mathrm{pH} 5,35^{\circ} \mathrm{C}, 0.1 \mathrm{mg} \cdot \mathrm{mL}^{-1}$ laccase. Baseline - oxygen consumption in laccase/buffer solution without substrate. 
Table 2. Effect of the laccase pre-treatment on the oxidative decolorization of fabrics, dyed with Reactive Yellow 160, Reactive Orange 16 and Reactive Green 19.

\begin{tabular}{llrrrrr}
\hline Dyes and wavelengths & Fabric in: & \multicolumn{2}{c}{$K / S$} & \multicolumn{2}{c}{ Decolorization } \\
\cline { 3 - 4 } & & dyed & laccase & bleach & \% \\
\hline R. Yellow 160, 430 nm & buffer & 9.17 & 8.75 & 3.01 & 67 \\
R. Green 19, 640 nm & laccase & 9.34 & 11.45 & 2.22 & 76 \\
R. Orange 16, 530 nm & buffer & 17.40 & 17.13 & 9.69 & 44 \\
& laccase & 17.34 & 17.21 & 4.83 & 72 \\
& buffer & 4.95 & 4.46 & 0.94 & 81 \\
& laccase & 5.08 & 4.79 & 0.51 & 90
\end{tabular}

Table 3. Effect of the laccase pre-treatment on the reduction of the amount of hydrogen peroxide.

\begin{tabular}{lccccc}
\hline & \multicolumn{5}{c}{$\mathrm{H}_{2} \mathrm{O}_{2}$} \\
\cline { 2 - 5 } & \multicolumn{5}{c}{$\mathrm{mL}$} \\
\cline { 2 - 5 } & 0.1 & 0.2 & 0.3 & 0.4 & 0.5 \\
\hline$W_{\text {perox. }}^{*}$ & - & - & - & - & 76.3 \\
$W_{\text {lac./perox. }}^{*}$ & 72.8 & 76.2 & 76.4 & 76.9 & 77.8
\end{tabular}

10 min. Afterward the samples were bleached in the same bath volume with increasing amounts of hydrogen peroxide - from 0.1 to $0.5 \mathrm{~mL} 35 \% \mathrm{H}_{2} \mathrm{O}_{2}$, at $\mathrm{pH} 11,95^{\circ} \mathrm{C}$, during $1 \mathrm{~h}$. The results in Table 3 show that the amount of hydrogen peroxide necessary to reach the whiteness of a fabric bleached with $0.5 \mathrm{~mL}$ peroxide could be reduced twice provided a laccase pre-treatment was performed. Lower amount of peroxide is beneficial in terms of reduced fiber damage during the high temperature and alkalinity bleaching process.

\section{Conclusion}

In this research the bleaching ability of laccase on cotton fabrics was tested. Laccases in low concentrations provided whiteness improvement on cellulosic fiber materials, which otherwise might be achieved performing repeated, high temperature and chemical consuming oxidizing operations. The short time of the enzymatic pre-treatment, sufficient to enhance fabric whiteness, renders this bio-process suitable for continuous operations. On the other hand a low-enzyme consuming laccase pre-treatment at mild conditions can reduce significantly the hydrogen peroxide dosage in subsequent chemical bleaching. The mechanism of laccase bleaching action is not fully understood, however the experiments support the hypothesis that the enzyme transforms the cellulose coloring matter in another colored compounds, which however are more easily susceptible to oxidation with peroxide and thus more easily degradable.

Acknowledgement: We would like to thank Marie-Curie Individual HPMF-CT-2000-00868 project for providing the grant to Dr. Tzanov.

[1] R. Bourbonnais, M. G. Paice, B. Freiermuth, E. Bodie, S Borneman, Appl. Environ. Microbiol. 1997, 12, 4627.

[2] A. Robles, R. Lucas, A. G. De Cienfuegos, A. Galvez, Enzyme Microb. Technol. 2000, 26, 484.

[3] A. Gardiol, R. Hernandez, B. Reinhammar, B. Harte, Enzyme Microb. Technol. 1996, 18, 347.

[4] A. L. Ghindilis, A. Makower, C. G. Bauer, F. F. Bier, F. W. Scheller, Anal. Chim. Acta 1995, 304, 25.

[5] G. Hublik, F. Schinner, Enzyme Microb. Technol. 2000, 27, 330.

[6] A. Lante, A. Crapisi, A. Krastanov, P. Spettoli, Process Biochem. 2000, 36, 51.

[7] F. Xu, Biochemistry 1996, 35, 7608.

[8] US 5795855 (1998), Novozymes A/S, invs.: P. Schneider, A. H. Pedersen.

[9] US 4485016 (1984), inv.: R. Thomas.

[10] R. Bourbonnais, M. G. Paice, Appl. Environ. Microbiol. 1992, 36, 823 .

[11] R. Bourbonnais, M. G. Paice, I. D. Reid, P. Lanthier, M. Yaguchi, Appl. Environ. Microbiol. 1995, 61, 1876.

[12] K. Li, F. Xu, K. E. L. Eriksson, Appl. Environ. Microbiol. 1999, 65, 2654.

[13] E. Abadula, T. Tzanov, S. Costa, K. H. Robra, A. CavacoPaulo, G. Guebitz, Appl. Environ. Microbiol. 2000, 66, 3357.

[14] M. Morita, R. Ito, T. Kamidate, H. Watanabe, Text. Res. J. 1996, 66, 470 .

[15] WO 9105839 (1991), Novo Nordisk A/S, The Procter \& Gamble Company, invs.: T. Damhus, G. Kirk, M. G. Pedersen, M. G. Venegas.

[16] WO 9612845 (1996), Novo Nordisk A/S, invs.: A. H. Pedersen, J. V. Kierulff.

[17] R. E. Childs, W. G. Bardsley, Biochem. J. 1975, 145, 93.

[18] US 2001037532 (2001), Novozymes A/S, invs.: M. Barfoed, O. Kirk, S. Salmon. 